\title{
Gonadal function in male patients after treatment for malignant lymphomas, with emphasis on chemotherapy
}

\author{
CE Kiserud ${ }^{*, 1}$, A Fosså2 ${ }^{2}$ T Bjøro ${ }^{3}$, H Holte ${ }^{2}$, M Cvancarova' and SD Fosså 1,4 \\ 'Department of Clinical Cancer Research, National Resource Center for long term effects after Cancer, Norwegian Radium Hospital, Rikshospitalet \\ University Hospital, Oslo 0310, Norway; ' Department of Oncology, Cancer Clinic, Nonwegian Radium Hospital, Rikshospitalet University Hospital, Oslo \\ 0310, Norway; ${ }^{3}$ Department of Medical Biochemistry, Rikshospitalet University Hospital and University of Oslo, Oslo, Norway; ${ }^{4}$ Faculty Division the \\ Nonwegian Radium Hospital, University of Oslo, Oslo O316, Norway
}

\begin{abstract}
Gonadal function was assessed in male lymphoma survivors based on serum hormone levels (LH, FSH, testosterone, SHBG), and was related to treatment, age and observation time. Male patients $\leqslant 50$ years at diagnosis treated for Hodgkin's (HL) and/or nonHodgkin's lymphoma (NHL) at the Norwegian Radium Hospital from I January 1980 to 3I December 2002 were included. Five treatment groups were defined: I: radiotherapy only and/or low gonadotoxic chemotherapy (both HL and $\mathrm{NHL}$ )('No/low'), 2: medium gonadotoxicity chemotherapy for NHL ('med-NHL'), 3: medium gonadotoxicity chemotherapy for HL ('med-HL'), 4: highly gonadotoxic chemotherapy for $\mathrm{NHL}$ ('high-NHL'), 5: highly gonadotoxic chemotherapy for HL ('high-HL'). Gonadal hormone levels were categorised into three groups: I: All gonadal hormones within normal range (normal), 2: Isolated elevated FSH, with LH, SHBG and testosterone within normal range (exocrine hypogonadism), 3: Testosterone below and/or LH above normal range (endocrine hypogonadism). One hundred and forty-four (49\%) of the patients had normal gonadal hormones, 60 (20\%) displayed exocrine hypogonadism and almost one-third $(n=90,30 \%)$ had endocrine hypogonadism. Compared to those treated with no/low gonadotoxic chemotherapy patients from all other treatment groups had significantly elevated risk for exocrine hypogonadism. Patients from the other treatment groups, except those in the med-NHL group, also had significantly elevated risk for endocrine hypogonadism compared with the group treated with no/low gonadotoxic chemotherapy. Men aged above 50 years at survey were about five times more likely to have endocrine hypogonadism compared with those less than 40 years. Because of the adverse health effects following long-lasting endocrine hypogonadism, gonadal hormones should be assessed regularly in male lymphoma survivors, especially after treatment with alkylating agents and high-dose chemotherapy with autologous stem cell support and in male patients who are 50 years and older.
\end{abstract}

British Journal of Cancer (2009) I 00, 455-463. doi:I0.I038/sj.bjc.6604892 www.bjcancer.com

Published online 20 January 2009

(c) 2009 Cancer Research UK

Keywords: male lymphoma survivors; chemotherapy; gonadal function

Testicular dysfunction can be a late side effect after cancer treatment. It is known that post-treatment spermatogenesis in male survivors after malignant lymphoma is dependent on the type of chemotherapy, the drugs' cumulative dose, the radiation doses to the testicles from scattered or direct irradiation and the time since last treatment (Lee et al, 2006).

Further, some studies have shown that pre-treatment spermatogenesis in survivors after Hodgkin's lymphoma (HLSs) is impaired at a greater degree than in survivors after non-Hodgkin's lymphoma (NHLSs) (Botchan et al, 1997; Fitoussi et al, 2000; Rueffer et al, 2001). Post-treatment gonadal dysfunction may thus be associated with pre-treatment fertility problems.

\footnotetext{
*Correspondence: Dr CE Kiserud;

E-mail: cecilie.essholt.kiserud@radiumhospitalet.no

Received 10 July 2008; revised 17 December 2008; accepted 18

December 2008; published online 20 January 2009
}

During recent years evidence has emerged that malignant lymphoma survivors may have subnormal serum levels of testosterone and/or elevated LH (Whitehead et al, 1982; Viviani et al, 1991; Howell et al, 1999) However, there are a few large studies confirming these findings, and even fewer studies are published which compare HLSs with NHLSs. On the other hand, endocrine hypogonadism may increase the risk of severe health problems such as premature osteoporosis and insulinresistance (Finkelstein et al, 1987; Howell et al, 2000; Greenfield et al, 2007).

In adult men the testicles have both endocrine (hormone production) and exocrine (spermatogenesis) function, controlled by the hypothalamus - pituitary - gonad axis. Gonadotropinreleasing hormone $(\mathrm{GnRH})$ from the hypothalamus promotes the production of the luteinizing hormone (LH) and follicle-stimulating hormone (FSH) from the anterior pituitary. Simplified, LH stimulates the Leydig cells to produce testosterone; FSH and testosterone stimulate the Sertoli cells, which together provide support for spermatogenesis. 
Gonadal dysfunction may be classified as primary and/or secondary hypogonadism. Primary hypogonadism is due to testicular damage resulting in impaired spermatogenesis and/or dysfunction of the Leydig cells. As a rule of thumb, elevated FSH indicates impaired spermatogenesis, whereas permanently elevated LH indicates Leydig cell dysfunction. Secondary hypogonadism is caused by damage to the pituitary gland or hypothalamus, that is, after cranial radiotherapy, and leads to decreased LH and FSH followed by both exocrine and endocrine gonadal failure. Male gonadal function can thus be screened by assessment of serum levels of LH, FSH, testosterone, SHBG and sperm cell count and by the consideration of fatherhood. In case of Leydig cell damage the serum levels of testosterone are low and those of $\mathrm{LH}$ are often elevated, though Greenfield et al (2007) recently has cast some doubt about this correlation.

With this background, the aim of the present cross-sectional study was to assess post-treatment gonadal function in a large series of lymphoma patients in relation to treatment, age and observation time emphasizing the possible differences between HLSs and NHLSs.

\section{PATIENTS AND METHODS}

\section{Patients}

Eligible patients for the present postal cross-sectional study fulfilled all the following criteria: 1 : male patients $\leqslant 50$ years at diagnosis, 2: treated for Hodgkin's lymphoma (HL) and/or nonHodgkin's lymphoma (NHL), 3: registered in the lymphoma database at the Norwegian Radium Hospital (NRH), 4: Period of diagnosis from 1 January 1980 to 31 December 2002, 5: age above 18 years at the time of the survey (January 2007), 6: valid postal address and 7: alive in June 2007.

Patients who had received total brain irradiation or scrotal irradiation were excluded. Patients registered with both HL and NHL was grouped according to their first diagnosis. Totally there were 16 patients, of whom seven had their gonadal hormones assessed. Of these seven, four were initially diagnosed with HL and three with NHL, and later on they were diagnosed with a secondary lymphoma.

\section{Treatment}

Treatment strategies of HL and NHL at the NRH for the period 1980 - 2002 have been described earlier (Hagemeister et al, 1987; Merk et al, 1991; Evensen et al, 1994; Abrahamsen et al, 1996; Holte et al, 1996; Hollender et al, 2000; Aurlien et al, 2001; Seidemann et al, 2001; Sweetenham et al, 2001; Blystad et al, 2001a, 2001b; Smeland et al, 2004; Kiserud et al, 2007).

For the purpose of this study the total treatment of each patient, thus both primary and eventual salvage therapy, was summarised as recorded in the lymphoma database. As there is little knowledge concerning damage of the Leydig cell function by chemotherapy, we have categorised chemotherapy according to the expected exocrine gonadal damage. Categories were created based mainly on literature on post-treatment exocrine hypogonadism, as reported in a previous study on post-treatment parenthood in HLSs: low, medium and high chemotherapy-induced gonadotoxicity (Viviani et al, 1985; Howell and Shalet, 2001; Lee et al, 2006; Kiserud et al, 2007). In addition, a group was constructed including patients who had received radiotherapy only.

Analyses showed no differences with respect to gonadal hormones between patients who had received supradiaphragmatic RT only and those who had been irradiated with inverted Y/ inguinal or other infradiaphragmatic fields. In addition, there was no difference between the group treated with radiotherapy only and the group treated with low gonadotoxic chemotherapy.
The treatment groups were defined as follows: 1: radiotherapy only and/or low gonadotoxic chemotherapy (both HL and NHL) ('No/low'), 2: medium gonadotoxicity chemotherapy for NHL ('med-NHL'), 3: medium gonadotoxicity chemotherapy for HL ('med-HL'), 4: highly gonadotoxic chemotherapy for NHL ('highNHL'), 5: highly gonadotoxic chemotherapy for HL ('high-HL'). The different chemotherapy regimens were allocated to groups $1-5$ as described in Table $1 \mathrm{~A}$, with chemotherapy regimens, number of courses and type of radiotherapy for each treatment group outlined in Tables $1 \mathrm{~B}$ and $1 \mathrm{C}$.

\section{Study design}

The cross-sectional study included serum hormone analyses and a questionnaire assessing various aspects of quality of life. The present analyses are restricted to gonadal hormones, whereas quality of life aspects will be discussed in detail in a separate paper.

Blood samples for analyses of gonadal hormones (testosterone, SHBG, LH, FSH) were to be drawn before noon by the patient's GP and mailed to the Hospital's Department of Medical Biochemistry. Patients with gonadal hormones indicating hypogonadism were invited to an outpatient clinical examination and a control morning blood sample. All analyses were performed at the same laboratory at Rikshospitalet with E170 module for Modular Analytics, Roche Professional Diagnostic, Germany. Normal ranges were: Testosterone: $9.0-31.0 \mathrm{nmoll}^{-1}$, SHBG: $15-85 \mathrm{nmoll}^{-1}, \mathrm{FSH}<12.0 \mathrm{Ul}^{-1}$, $\mathrm{LH}<10.0 \mathrm{Ul}^{-1}$. The testosterone/SHBG ratio was calculated for each patient, as a surrogate for free testosterone, with testosterone/SHBG ratio $<0.25$ indicating hypogonadism.

Table IA Groups of chemotherapy according to expected gonadotoxicity

\begin{tabular}{|c|c|}
\hline Treatment groups & Treatment \\
\hline $\begin{array}{l}\text { I. No chemotherapy/ } \\
\text { Low gonadotoxic } \\
\text { chemotherapy } \\
\text { (both HL and NHL) } \\
\text { No/low }\end{array}$ & $\begin{array}{l}\text { Radiotherapy only } \\
\text { ABVD/EBVP and similar }\end{array}$ \\
\hline $\begin{array}{l}\text { 2. Medium gonadotoxic } \\
\text { chemotherapy NHL } \\
\text { Med-NHL }\end{array}$ & $\begin{array}{l}\text { CHOP/COP/CHOEP } \\
\leqslant 8 \text { courses alone } \\
\text { CHOP } \leqslant 8 \text { courses combined with high dose Mtx } \\
\text { MACOP B } \\
\text { BFM } 90 / 93 \\
\text { Chlorambucil p.o. } \\
\text { MIME }\end{array}$ \\
\hline $\begin{array}{l}\text { 3. Medium gonadotoxic } \\
\text { chemotherapy HL }\end{array}$ & $\begin{array}{l}\text { LVPP } \leqslant 4 \text { courses alone or combined with ABOD/ } \\
\text { EBVP/dexa BEAM ( } 2 \text { courses) } \\
\text { OEPA+0 } 4 \text { COPP } \\
\text { MIME }\end{array}$ \\
\hline $\begin{array}{l}\text { 4. Highly gonadotoxic } \\
\text { chemotherapy NHL }\end{array}$ & $\begin{array}{l}\mathrm{CHOP}>8 \text { courses } \\
\mathrm{CHOP}=8 \text { courses combined with MIME, ENAP or } \\
\text { Chlorambucil } \\
\text { Maxi-CHOP } \geqslant 6 \text { courses }\end{array}$ \\
\hline High-NHL & $\begin{array}{l}\text { HDT with BEAM as conditioning regimen } \\
\text { HDT with cyclophosphamide and TBI as conditioning } \\
\text { regimen }\end{array}$ \\
\hline $\begin{array}{l}\text { 5. Highly gonadotoxic } \\
\text { chemotherapy HL }\end{array}$ & $\begin{array}{l}\text { LVPP }>4 \text { courses } \\
\text { LVPP }=4 \text { courses combined with CHOP, MIME or } \\
\text { BEACOPP ( } 4 \text { courses }) \\
\text { BEACOPP } 8 \text { courses }\end{array}$ \\
\hline High-HL & $\begin{array}{l}\text { HDT with BEAM as conditioning regimen } \\
\text { HDT with cyclophosphamide and TBI as conditioning } \\
\text { regimen }\end{array}$ \\
\hline
\end{tabular}

$\mathrm{HDT}=$ high-dose chemotherapy with autologous stem cell support; $\mathrm{TBI}=$ total body irradiation. 
Chemotherapy regimens with cumulative doses of alkylating agents and procarbazine used in the five treatment groups

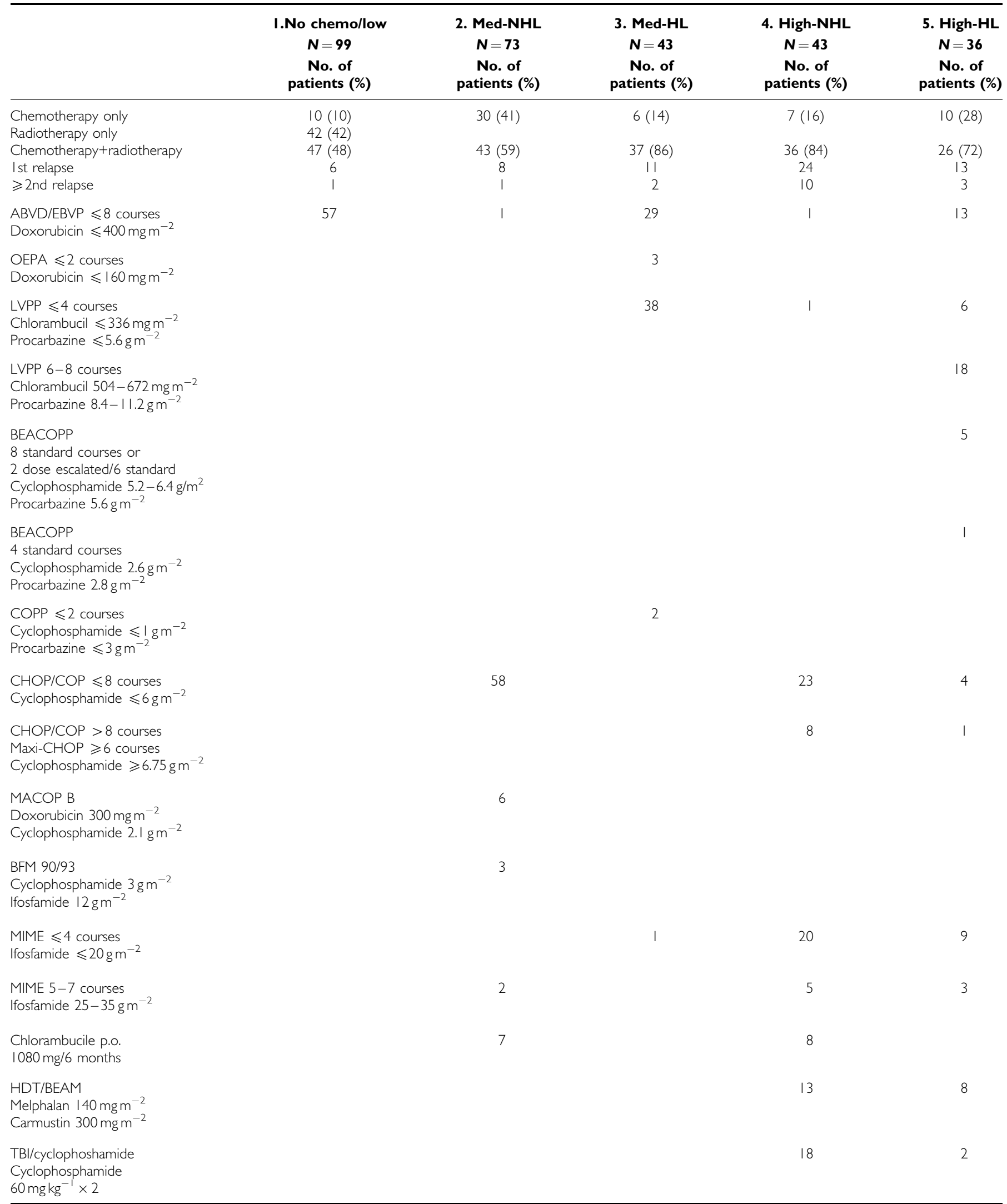

$\overline{A B V D}=$ doxorubicin, bleomycin, vinblastine, dacarbazine; BEACOPP = cyclophosphamide, doxorubicin, etoposide, procarbazine, prednisone, vincristine, bleomycine; $\mathrm{BEAM}=$ carmustine, etoposide, cytarabine, melphalan; $\mathrm{CHOP}=$ cyclophosphamide, doxorubicin, vincristine, prednisone; LVPP, chlorambucile, vinblastine, procarbazine, prednisone; MACOP-B, methotrexate, doxorubicin, cyclophosphamide, vincristine, prednisone, bleomycin; MIME, mitoguazone, iphosphamide, methotrexate, etoposide; OEPA, doxorubicine, vincristine, etoposide, prednisone. Number of patients =294. BFM 90/93 as described by Seidemann et al, 200 I, see reference list. 
Table IC Radiotherapy treatment in the five treatment groups

\begin{tabular}{|c|c|c|c|c|c|}
\hline & $\begin{array}{l}\text { I. No chemo/low } \\
\begin{array}{c}N=99 \\
(\%)\end{array}\end{array}$ & $\begin{array}{l}\text { 2. Med-NHL } \\
\begin{array}{c}N=73 \\
(\%)\end{array}\end{array}$ & $\begin{array}{l}\text { 3. Med-HL } \\
\begin{array}{l}N=43 \\
(\%)\end{array}\end{array}$ & $\begin{array}{l}\text { 4. High-NHL } \\
\begin{array}{l}N=43 \\
(\%)\end{array}\end{array}$ & $\begin{array}{l}\text { 5. High-HL } \\
\begin{array}{c}N=36 \\
(\%)\end{array}\end{array}$ \\
\hline Supradiaphragmatic & 73 & 22 & 24 & 11 & 15 \\
\hline Abdominal fields & 3 & 16 & 3 & 3 & 4 \\
\hline InvertedY/Inguinal fields & 10 & 4 & 9 & 3 & 5 \\
\hline TBI & & & & 18 & 2 \\
\hline
\end{tabular}

Number of patients=294. HL: Stage 1/I: 1980-1982: 2 Gy $\times 20$, 1982-1998: 1.8 Gy × 23, 1999 onwards: 1.75 Gy $\times$ 17. Stage III/IV: 1980-1985: 2 Gy $\times 20$, 1985-1998: $2 \mathrm{~Gy} \times 20$ or I.8 Gy $\times 23$, 1999 onwards: $1.75 \mathrm{~Gy} \times 17$. NHL: Low-grade: $2 \mathrm{~Gy} \times 15$ to involved and nearest neighbouring draining lymph node region. High-grade: $2 \mathrm{~Gy} \times 20$ or

$1.8 \mathrm{~Gy} \times 23$ if residual masses or initial Bulky disease. TBI (total body irradiation): $1.3 \mathrm{~Gy} \times 10$.

Table 2 Patients characteristics

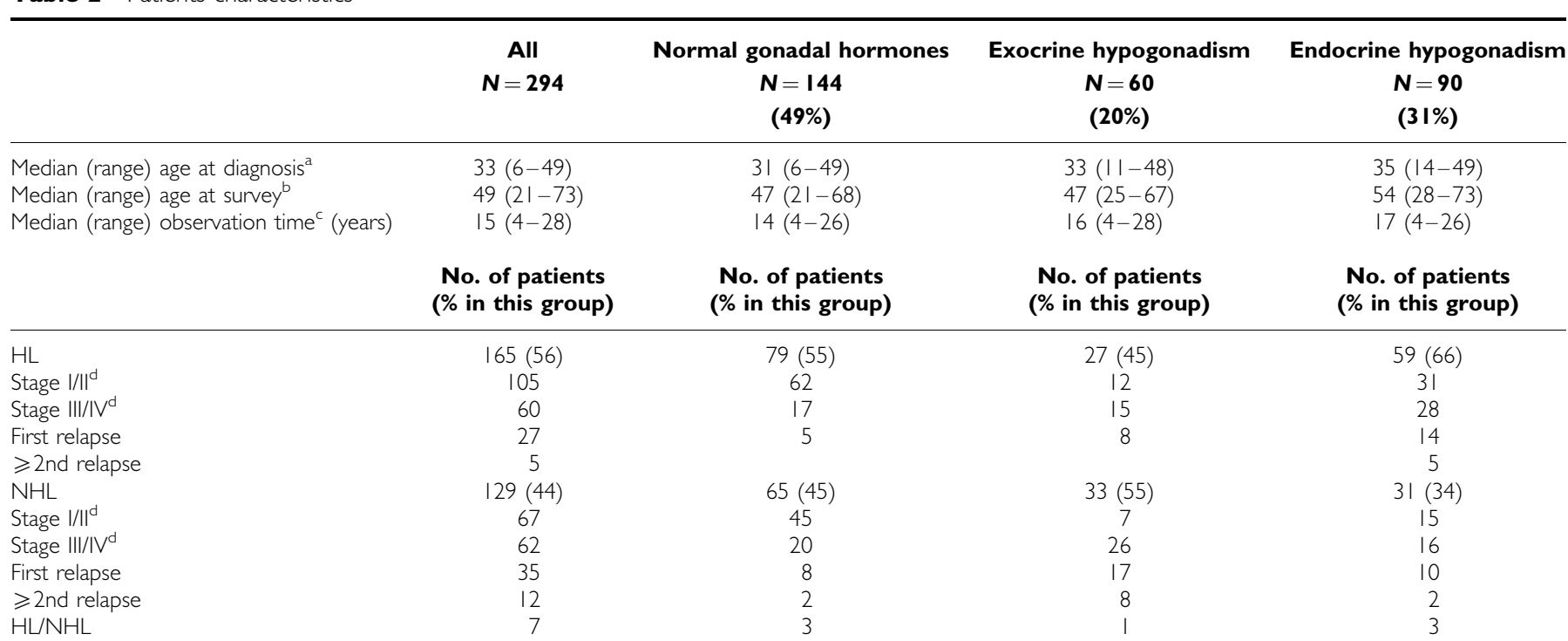

\begin{tabular}{|c|c|c|c|c|}
\hline Treatment group & $\begin{array}{l}\text { No. of patients } \\
\text { (\% in this group) }\end{array}$ & No. of patients & No. of patients & No. of patients \\
\hline I. No chemo/Low & $99(34)$ & 78 & 3 & 18 \\
\hline 2. Med-NHL & $73(25)$ & 45 & 13 & 15 \\
\hline 4. High-NHL & $43(15)$ & 7 & 20 & 16 \\
\hline HDT/BEAM & 13 & I & 8 & 4 \\
\hline TBI/cyclophoshamide & 18 & I & 7 & 10 \\
\hline HDT/BEAM & 8 & & 4 & 4 \\
\hline TBI/cyclophoshamide & 2 & & & 2 \\
\hline
\end{tabular}

Exocrine hypogonadism: $\mathrm{FSH}>12.0 \mathrm{UI}^{-1}$; testosterone, SHBG, $\mathrm{LH}$ within normal ranges. Endocrine hypogonadism: Either testosterone $<9.0 \mathrm{nmol} \mathrm{I}^{-1}$ and/or elevated $\mathrm{LH}$. Treatment groups: I: No/Low gonadotoxic chemotherapy \pm radiotherapy. 2: Medium gonadotoxic chemotherapy \pm radiotherapy NHL. 3: Medium gonadotoxic chemotherapy \pm radiotherapy $\mathrm{HL}$. 4: High gonadotoxic chemotherapy \pm radiotherapy $\mathrm{NHL}$. 5: High gonadotoxic chemotherapy \pm radiotherapy HL. ${ }^{2} \mathrm{Age}$ at diagnosis: $P=0.017$, Kruskal-Wallis (among groups of gonadal hormones). ${ }^{b}$ Age at survey: $P=0.00 \mathrm{I}$, Kruskal-Wallis (among groups of gonadal hormones). ${ }^{\mathrm{c}} \mathrm{Observation}$ time: time from diagnosis to I January 2007 (in years). dStage at initial diagnosis. HDT = high dose chemotherapy with autologous stem cell support. HU/NHL = patients registered with both diagnosis in the lymphoma database.

The patients' gonadal hormone levels were categorised into three groups: 1: All gonadal hormones within normal range (Normal), 2: Isolated elevated FSH, with LH, SHBG and testosterone within normal range (exocrine hypogonadism), 3: Testosterone below and/or LH above normal range, independent of FSH (endocrine hypogonadism), admitting that this group includes some male patients with both endocrine and exocrine hypogonadism. (Table 2 ).
Patients with endocrine hypogonadism were further subgrouped: A: low testosterone and normal LH/FSH, B: elevated $\mathrm{LH}$, testosterone normal, $\mathrm{C}$ : low testosterone combined with either elevated LH and/or elevated FSH. (Table 3).

Three patients already on testosterone substitution were included in subgroup $\mathrm{C}$, assuming they had low testosterone combined with elevated $\mathrm{LH}$ before having started testosterone substitution. 
Table 3 Characteristics of the patients with endocrine hypogonadism, and subgroups

\begin{tabular}{lcccc}
\hline & $\begin{array}{c}\text { Endocrine } \\
\text { hypogonadism } \\
\mathbf{N}=\mathbf{9 0}\end{array}$ & $\begin{array}{c}\text { A. } \\
\text { Low testosterone } \\
\text { LH/FSH normal } \\
\mathbf{N}=\mathbf{2 7}\end{array}$ & $\begin{array}{c}\text { B. } \\
\text { Elevated LH } \\
\text { Testosterone normal } \\
\mathbf{N}=\mathbf{3 0}\end{array}$ & $\begin{array}{c}\text { Low testosterone } \\
\text { Elevated LH or FSH or both }\end{array}$ \\
$\mathbf{N}=\mathbf{3 3}$
\end{tabular}

Treatment groups: I: No/Low gonadotoxic chemotherapy \pm radiotherapy. 2: Medium gonadotoxic chemotherapy \pm radiotherapy NHL. 3: Medium gonadotoxic chemotherapy \pm radiotherapy HL. 4: High gonadotoxic chemotherapy \pm radiotherapy NHL. 5: High gonadotoxic chemotherapy \pm radiotherapy HL. ${ }^{a}$ Elevated FSH and low testosterone: $n=17$, elevated both $\mathrm{LH}$ and FSH and low tesosterone $n=16$.

\section{Ethical considerations}

Informed written consent was obtained from all responders. The Regional Committee for Medical Research Ethics, Health Region South, Norway and the Institutional Review Board and the Chief Privacy Officer at the NRH approved the study.

\section{Statistical analyses}

Data were described with medians and ranges. Continuous variables were compared using Mann-Whitney Wilcoxon and Kruskal-Wallis tests. Crude associations between categorical variables were computed with $\chi^{2}$ tests.

Age at diagnosis was categorised into four groups: 1: 6-25 years, 2: 26-34 years, 3: 35-41 years, 4: $42-50$ years. Age at survey (January 2007) was categorised as follows: 1: 21-39 years, 2: 40-49 years, 3: 50-56 years, 4: 57-75 years. Observation time was calculated from date of first diagnosis to 1 January 2007, and was further categorised in three groups: 1: 4-10 years, 2: 11-20 years, 3: $21-28$ years.

Multinomial regression analyses were performed, the dependent variable being gonadal hormones divided into three categories: $(1=$ normal (reference), 2 = exocrine hypogonadism, $3=$ endocrine hypogonadism). The model was adjusted for the five treatment groups, age groups and observation time. As initial analyses revealed that observation time was not significant, this variable was excluded from the final model. Finally, two multivariable models were fitted; one including treatment groups and age at survey as independent variables, the other included treatment groups and age at diagnosis. The odds ratios for both exocrine and endocrine hypogonadism were similar in both models, possibly due to a strong correlation between age at diagnosis and age at survey. Only results from the model fitted with treatment and age at survey are presented.

$P<0.05$ were considered statistically significant (all tests were two-sided). All analyses were performed using SPSS 13 for Windows.

\section{RESULTS}

\section{Patients' characteristics}

In all 653 patients met the inclusion criteria and were invited to participate by mail ( $360 \mathrm{HL}, 293 \mathrm{NHL})$. A total of 294 (45\%) had their gonadal hormones assessed and were included in this study (compliers).

The compliers and non-compliers (survivors without blood samples) were similar as to lymphoma diagnosis and treatment groups. However, the compliers were older than the non-compliers both at diagnosis (median 33 vs 31 years $(P=0.006)$ ) and at survey (median 49 vs 45 years $(P<0.001)$ ), and had significantly longer observation time (median 15 vs 13 years $(P=0.028)$ ).

Of the 294 compliers, 165 (56\%) had been treated for HL and 129 $(44 \%)$ for NHL. Sixty-four percent $(n=187)$ had received chemotherapy and radiotherapy, 63 (21\%) had had chemotherapy only and 44 patients (15\%) had undergone radiotherapy only. Median age at diagnosis was 33 years (range, 6-49), median age at survey was 49 years (range, 21-73), and median observation time was 15 years (range, $4-28$ ) (Table 2).

As expected, age at survey and age at diagnosis were higher in NHLSs compared with HLSs, without difference in observation time between these groups.

\section{Single values of FSH, LH, Testosterone and SHBG}

The median FSH value for all patients was $8.5 \mathrm{Ul}^{-1}$ (range, $\left.0.4-67.0 \mathrm{Ul}^{-1}\right)$. Forty-one percent had FSH values $>12.0 \mathrm{Ul}^{-1}$, and in $26 \%$ the FSH value were $>20.0 \mathrm{Ul}^{-1}$. The median $\mathrm{LH}$ value was $6.0 \mathrm{Ul}^{-1}$ (range, $1.2-45.8 \mathrm{Ul}^{-1}$ ), and $16 \%$ of the patients had elevated LH $\left(>10.0 \mathrm{Ul}^{-1}\right.$ ) (Table 4).

The median testosterone value was $12.9 \mathrm{nmoll}^{-1}$ (range, 1.7-33.9 $\mathrm{nmoll}^{-1}$ ), with $20 \%$ of the patients having testosterone value $<9.0 \mathrm{nmoll}^{-1}$. The median value of the testosterone/ SHBG-ratio was 0.37 . Of all patients, $14 \%$ had a testosterone/ SHBG ratio $<0.25$. 
Table 4 Serum levels of LH, FSH, testosterone, SHBG and testosterone/SHBG ratio related to age at survey and treatment groups

\begin{tabular}{|c|c|c|c|c|c|c|c|c|c|c|}
\hline & \multicolumn{5}{|c|}{ Age at survey groups } & \multicolumn{5}{|c|}{ Treatment groups } \\
\hline & $\begin{array}{c}\text { All } \\
N=294\end{array}$ & $\begin{array}{c}I \\
21-39 y r s \\
N=66\end{array}$ & $\begin{array}{c}2 \\
40-49 y r s \\
N=86\end{array}$ & $\begin{array}{c}3 \\
50-56 \mathrm{yrs} \\
N=75\end{array}$ & $\begin{array}{c}4 \\
57-75 \text { yrs } \\
N=67\end{array}$ & $\begin{array}{c}\text { I } \\
\text { No/low } \\
\mathbf{N}=99\end{array}$ & $\begin{array}{c}2 \\
\text { med-NHL } \\
N=73\end{array}$ & $\begin{array}{c}3 \\
\text { med-HL } \\
N=43\end{array}$ & $\begin{array}{c}4 \\
\text { high-NHL } \\
N=43\end{array}$ & $\begin{array}{c}5 \\
\text { high-HL } \\
n=36 \\
\end{array}$ \\
\hline \multicolumn{11}{|l|}{ FSH } \\
\hline $\begin{array}{l}\text { Median } \\
\text { Range }\left(\mathrm{UI}^{-1}\right) \\
\mathrm{FSH}>12 \mathrm{UI}^{-1}\end{array}$ & $\begin{array}{c}8.5 \\
0.4-67.0 \\
41 \%\end{array}$ & $\begin{array}{c}5.9 \\
1.0-32.0 \\
31 \%\end{array}$ & $\begin{array}{c}6.4 \\
1.4-67.0 \\
32 \%\end{array}$ & $\begin{array}{c}8.5 \\
2.3-56.4 \\
43 \%\end{array}$ & $\begin{array}{c}17.7 \\
0.4-63.3 \\
59 \%\end{array}$ & $\begin{array}{c}4.7 \\
1.0-40.4 \\
5 \%\end{array}$ & $\begin{array}{r}7.2 \\
1.4-41 \\
33 \%\end{array}$ & $\begin{array}{c}19.8 \\
2.2-56.4 \\
70 \%\end{array}$ & $\begin{array}{c}19.2 \\
2.3-67.0 \\
81 \%\end{array}$ & $\begin{array}{c}20.5 \\
0.4-53.2 \\
81 \%\end{array}$ \\
\hline \multicolumn{11}{|l|}{$L H$} \\
\hline $\begin{array}{l}\text { Median } \\
\text { Range } U^{-1} \\
\mathrm{LH}>\mid 0 \mathrm{UI}^{-1}\end{array}$ & $\begin{array}{c}6.0 \\
1.2-45.8 \\
16 \%\end{array}$ & $\begin{array}{c}5.7 \\
1.8-14.5 \\
10 \%\end{array}$ & $\begin{array}{c}5.5 \\
1.7-20.1 \\
7 \%\end{array}$ & $\begin{array}{c}5.7 \\
1.8-26.3 \\
23 \%\end{array}$ & $\begin{array}{c}7.7 \\
1.2-45.8 \\
25 \%\end{array}$ & $\begin{array}{c}4.4 \\
1.7-16.7 \\
3 \%\end{array}$ & $\begin{array}{c}5.4 \\
1.2-43.6 \\
12 \%\end{array}$ & $\begin{array}{c}7.9 \\
1.9-19.6 \\
30 \%\end{array}$ & $\begin{array}{c}8.2 \\
2.3-45.8 \\
29 \%\end{array}$ & $\begin{array}{c}8.2 \\
4.5-20.1 \\
32 \%\end{array}$ \\
\hline \multicolumn{11}{|l|}{ Testosterone } \\
\hline $\begin{array}{l}\text { Median } \\
\text { Range }(\text { nmol I-1) } \\
\text { Testosterone }<9 \text { nmoll-1 }^{-1}\end{array}$ & $\begin{array}{c}12.9 \\
1.7-33.9 \\
20 \%\end{array}$ & $\begin{array}{c}13.6 \\
4.4-28.1 \\
12 \%\end{array}$ & $\begin{array}{c}13.7 \\
4.7-33.9 \\
16 \%\end{array}$ & $\begin{array}{c}12.8 \\
4.3-26.6 \\
24 \%\end{array}$ & $\begin{array}{c}11.1 \\
1.7-23.0 \\
28 \%\end{array}$ & $\begin{array}{c}12.6 \\
5.2-27.1 \\
17 \%\end{array}$ & $\begin{array}{c}14.3 \\
1.7-30.4 \\
\mid 4 \%\end{array}$ & $\begin{array}{c}10.2 \\
5.4-33.9 \\
33 \%\end{array}$ & $\begin{array}{c}14.2 \\
4.3-22.4 \\
15 \%\end{array}$ & $\begin{array}{c}11.3 \\
4.4-29.6 \\
33 \%\end{array}$ \\
\hline \multicolumn{11}{|l|}{ Testosterone/SHBG ratio } \\
\hline $\begin{array}{l}\text { Median } \\
\text { Range } \\
\text { Testosterone/SHBG ratio }<0.25\end{array}$ & $\begin{array}{c}0.37 \\
0.05-1.02 \\
14 \%\end{array}$ & $\begin{array}{c}0.49 \\
0.18-1.02 \\
3 \%\end{array}$ & $\begin{array}{c}0.42 \\
0.13-0.85 \\
9 \%\end{array}$ & $\begin{array}{c}0.32 \\
0.14-0.65 \\
15 \%\end{array}$ & $\begin{array}{c}0.28 \\
0.05-0.56 \\
30 \%\end{array}$ & $\begin{array}{c}0.42 \\
0.13-0.78 \\
13 \%\end{array}$ & $\begin{array}{c}0.35 \\
0.05-0.84 \\
10 \%\end{array}$ & $\begin{array}{c}0.31 \\
0.14-1.02 \\
24 \%\end{array}$ & $\begin{array}{c}0.36 \\
0.1-0.7 \mid \\
15 \%\end{array}$ & $\begin{array}{c}0.39 \\
0.1-0.85 \\
14 \%\end{array}$ \\
\hline
\end{tabular}

Age at survey categorised in four groups: 1: 21-39 years, 2: 40-49 years, 3: $50-56$ years, 4: $57-75$ years. Treatment groups: I: No/Low gonadotoxic chemotherapy \pm radiotherapy. 2: Medium gonadotoxic chemotherapy \pm radiotherapy $\mathrm{NHL}$. 3: Medium gonadotoxic chemotherapy \pm radiotherapy HL. 4: High gonadotoxic chemotherapy \pm radiotherapy $\mathrm{NHL}$. 5: High gonadotoxic chemotherapy \pm radiotherapy $\mathrm{HL}$

There was a significant association between age at survey and the individual levels of FSH, LH and SHBG $(P<0.001)$. For testosterone, no such association with age at survey was observed. However, the testosterone/SHBG-ratio decreased significantly with increasing age $(P<0.001)$.

There was also a significant association between the individual levels of both FSH, LH $(P<0.001)$ and SHBG $(P=0.042)$ and treatment groups. The median level of FSH and $\mathrm{LH}$ increased significantly in all other treatment groups compared with patients with no/low gonadotoxic chemotherapy $(P<0.001-P<0.02)$. For testosterone and testosterone/SHBG-ratio no association with treatment groups was found.

\section{Groups of gonadal dysfunction}

Forty-nine percent $(n=144)$ had all gonadal hormones within normal ranges, $60(20 \%)$ displayed exocrine hypogonadism (isolated elevated FSH, with LH, SHBG and testosterone within normal range) and in almost one-third ( $n=90,30 \%)$ the hormone levels were compatible with endocrine hypogonadism (testosterone below and/or LH above normal range, independent of FSH). There was a statistically significant association between treatment group and groups of gonadal dysfunction $(P<0.001)$. After treatment with no/low gonadotoxic chemotherapy $79 \%$ had normal gonadal hormones, whereas the comparable figures were $62 \%$ after med-NHL, $26 \%$ after med-HL, 16\% after high-NHL and $8 \%$ after high-HL (Figure 1; (Table 2).

Of the 41 patients treated with high dose chemotherapy and autologous stem cell support (HDT), 19 men had exocrine and 20 endocrine hypogonadism. Only two patients had normal gonadal hormones.

Stage at diagnosis was significantly associated with the group of hormonal dysfunction $(P<0.001)$. In patients with stage I/II at diagnosis $62 \%$ had normal gonadal hormones, $11 \%$ displayed exocrine hypogonadism and endocrine hypogonadism was demonstrated in $27 \%$. The comparable numbers in patients with stage III/IV were: normal gonadal hormones in 30\%, exocrine hypogonadism in $34 \%$ and endocrine hypogonadism in $36 \%$.

The patients with endocrine hypogonadism were older both at diagnosis $(P=0.004)$ and at survey $(P<0.001)$ and they had a longer median observation time $(P=0.047)$ than those with normal gonadal hormones. There was no difference in age at diagnosis or survey and in observation times between patients with exocrine hypogonadism and patients with normal gonadal hormones.

\section{Multinomial regression analyses}

Compared to those treated with no/low gonadotoxic chemotherapy patients from all other treatment groups had significantly elevated odds ratios (OR) for exocrine hypogonadism (Table 5). Patients in the med-NHL group were 6.3 (95\% CI: 1.7-23.8) times more likely to suffer from exocrine hypogonadism compared to those treated with no/low gonadotoxic chemotherapy. The comparable ORs for the other groups were 25.7 (95\% CI: 6.2-107.0) after med-HL, 73.3 (95\% CI: 17.2-312.2) after high-NHL and 112.0 (95\% CI: $20.1-$ 625.2) after high-HL. Age at survey was not significantly associated with exocrine hypogonadism.

In addition, compared to the group treated with no/low gonadotoxic chemotherapy, patients from the other treatment groups, except those in the med-NHL group, had significantly elevated risk also for endocrine hypogonadism. Patients in the med-HL were 8.0 (95\% CI: $3.2-20.4$ ) times more likely to have endocrine hypogonadism compared to those treated with no/low gonadotoxic chemotherapy, whereas the comparable ORs for highNHL were 10.5 (95\% CI: 3.6-30.6) and 37.2 (95\% CI: 9.4-147.7) for high-HL. 


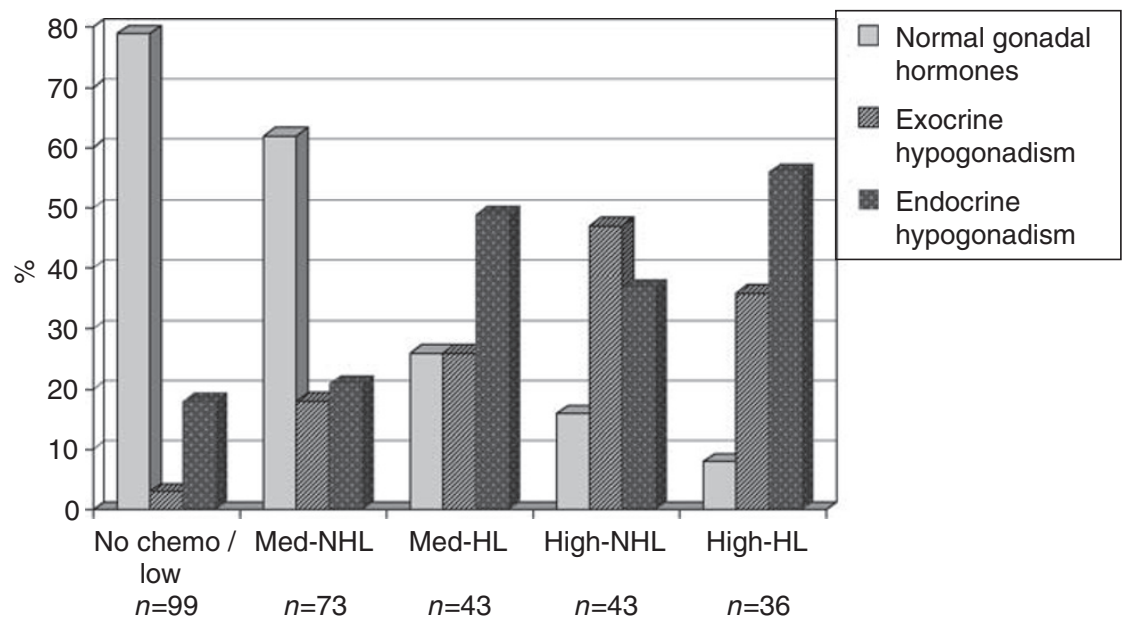

Figure I Proportions of male lymphoma survivors with normal gonadal hormones, exocrine and endocrine hypogonadism. Normal gonadal hormones: testosterone, SHBG, LH and FSH within normal ranges. Exocrine hypogonadism: isolated elevated FSH. Testosterone, SHBG, LH, within normal ranges. Endocrine hyogonadism: elevated LH and/or low testosterone. Treatment groups: No chemo/low: radiotherapy only/low gonadotoxic chemotherapy, MedNHL: medium gonadotoxic chemotherapy for non-Hodgkin's lymphoma (NHL), Med-HL: medium gonadotoxic chemotherapy for Hodgkin's lymphoma $(\mathrm{HL})$, High-NHL: highly gonadotoxic chemotherapy for $\mathrm{NHL}$, High-HL: highly gonadotoxic chemotherapy for HL.

Table 5

\begin{tabular}{|c|c|c|c|}
\hline & OR & $95 \% \mathrm{Cl}$ & $P$-value \\
\hline \multicolumn{4}{|l|}{ Exocrine hypogonadism } \\
\hline \multicolumn{4}{|l|}{ Treatment } \\
\hline I.No/low & Reference & & \\
\hline 2.Med-NHL & 6.3 & $1.7-23.8$ & 0.007 \\
\hline 3.Med-HL & 25.7 & $6.2-107.0$ & $<0.001$ \\
\hline 4.High-NHL & 73.3 & $17.2-312.2$ & $<0.001$ \\
\hline 5.High-HL & 112.0 & $20.1-625.2$ & $<0.001$ \\
\hline \multicolumn{4}{|l|}{ Age at survey } \\
\hline $1: 21-39$ years & Reference & & \\
\hline 2: $40-49$ years & 1.0 & $0.4-2.7$ & 0.96 \\
\hline 3: $50-56$ years & 1.0 & $0.3-3.0$ & 0.99 \\
\hline 4: $57-75$ years & 2.0 & $0.7-5.8$ & 0.19 \\
\hline \multicolumn{4}{|l|}{ Endocrine hypogonadism } \\
\hline \multicolumn{4}{|l|}{ Treatment } \\
\hline I.No/low & Reference & & \\
\hline 2.Med-NHL & I.I & $0.5-2.5$ & 0.86 \\
\hline 3.Med-HL & 8.0 & $3.2-20.4$ & $<0.001$ \\
\hline 4.High-NHL & 10.5 & $3.6-30.6$ & $<0.001$ \\
\hline 5.High-HL & 37.2 & $9.4-147.7$ & $<0.001$ \\
\hline \multicolumn{4}{|l|}{ Age at survey } \\
\hline 1: $21-39$ years & Reference & & \\
\hline 2: $40-49$ years & 1.5 & $0.5-3.9$ & 0.46 \\
\hline $3: 50-56$ years & 5.0 & $1.9-13.2$ & 0.001 \\
\hline 4: $57-75$ years & 4.9 & $1.8-13.7$ & 0.002 \\
\hline
\end{tabular}

Men aged above 50 years at survey were about five times more likely to have endocrine hypogonadism compared with those less than 40 years at survey.
The ORs for both isolated elevated FSH and endocrine hypogonadism increased more in HL survivors compared with NHL survivors in comparable treatment groups.

Overall, treatment with medium and highly gonadotoxic chemotherapy for both HL and NHL had a stronger effect on exocrine than on endocrine hypogonadism.

\section{Patients with endocrine hypogonadism $(n=90)$}

Patients with low testosterone combined with elevated LH and/or FSH displayed significantly longer observation times than the other two subgroups $(P=0.001)$. This group had also significantly lower testosterone/SHBG ratios than the other subgroups $(P=0.003 / P=0.001)$. (Table 3$)$.

\section{DISCUSSION}

In this cross-sectional observational study gonadal hormones were assessed in 294 male survivors after treatment for both HL and NHL. About half had all gonadal hormones within normal range, $20 \%$ had isolated elevated FSH, and almost one-third had gonadal hormones compatible with our definition of endocrine hypogonadism. Compared to those treated with no/low gonadotoxic chemotherapy, patients from all other treatment groups had significantly elevated risk for exocrine hypogonadism. In addition, patients from the other treatment groups, except those in the medNHL group, had a significantly elevated risk also for endocrine hypogonadism compared to the group treated with no/low gonadotoxic chemotherapy.

We confirm the results from our previous study in HLSs, where we observed exocrine gonadal damage related to the type, cumulative dose and intensity of chemotherapy, assessed by post-treatment paternity (Kiserud et al, 2007). This study shows for the first time that the same categorization of chemotherapy in low, medium and highly gonadotoxic treatment can be useful also when exploring endocrine hypogonadism.

Forty-one percent of our lymphoma survivors had elevated FSH. Although this figure seems comparable to $35 \%$, reported by van der Kaaij et al (2007), important differences should not be 
overseen. Our series included men with initially advanced disease and men treated for relapse. Many of our patients thus have had more intensive chemotherapy than usually given to patients with stage I/II. In addition, we examined both HLSs and NHLSs, which make the two series less comparable. Finally, our median observation time was 15 years, compared with the median 32 months follow-up period reported by van der Kaaij et al (2007). We thus consider our proportion of FSH elevation as definite, whereas one still can expect some recovery of spermatogenesis with longer follow up in early stage lymphoma patients with limited treatment.

This study confirms the low risk of elevated FSH in HLSs after treatment with ABVD-like regimens or radiotherapy only compared with other combinations incorporating alkylating agents (Whitehead et al, 1982; Viviani et al, 1985, 1991; van der Kaaij et al, 2007). In addition, we observed that the probability of exocrine hypogonadism increased with treatment intensity also in NHLSs, whereas age at survey was of no significance.

Compared to the no/low gonadotoxic chemotherapy group the risk of endocrine hypogonadism increased for all treatment groups except for NHLSs treated mainly with CHOP-based chemotherapy (med-NHL). Intensification of chemotherapy increased the risk of endocrine gonadal failure more in HLSs than in NHLSs. This probably reflects that chemotherapy regimens used for HL generally are more gonadotoxic than those used for NHL. This difference may also be due to differences in the pre-treatment gonadal function between HLSs and NHLSs, pointed out by Botchan et al (1997). Increasing risk of endocrine hypogonadism along with chemotherapy intensification has also been documented for testicular cancer survivors (Nord et al, 2003).

In this paper, we followed the categorisation for endocrine hypogonadism based on elevated $\mathrm{LH}$ and normal testosterone (compensated hypogonadism) or low testosterone with or without elevated LH proposed by Howell et al (1999). Our data indicated that the duration of the observation time might be associated with the development of an uncompensated hypogonadism, as this period was longer in subgroup $3 \mathrm{C}$ than in subgroup $3 \mathrm{~A}$ and $3 \mathrm{~B}$. However, our patient sample also shows a more diverse picture, with 27 of 57 patients with low testosterone having normal LH (subgroup 3A). Similarly, Greenfield et al (2007) reported low testosterone values $\left(<10 \mathrm{nmoll}^{-1}\right)$ in $24(13.6 \%)$ of 176 patients, but only eight of these men had increased LH. This may reflect that causes of endocrine hypogonadism in cancer survivors may be more complex than previously described. Chemotherapy and/or radiation-induced damage may develop either in the gonads, the hypothalamuspituitary axis or as a combination of these two. To verify the influence of secondary hypogonadism, the pituitary function has to be tested by a gonadotropin-releasing hormone test, which was not performed in our patients. Further, except for the pathway through the hypothalamus-pituitary axis and the release of $\mathrm{GnRH}$, the mechanisms related to Leydig cell dysfunction after cancer treatment is not well characterised. The possible negative influence of germinative dysfunction on Leydig cells suggested by Howell et al (1999) is thus interesting, but requires further examination.

The blood samples were generally taken during the morning. We were aware of the risk of falsely low testosterone in case of afternoon blood sampling and tried to avoid this possibility as much as possible. However, we completely cannot exclude such sampling as explanation in some patients in subgroup 3A. For most of these patients, the results have been confirmed in a subsequent morning sample taken at the hospital's outpatient clinic, as patients with gonadal hormones indicating hypogonadism were invited to clinical examination and a control morning blood sample. Finally, a low testosterone value with normal LH and FSH may also be due to a random low testosterone value caused by, for instance patients' stress.

Testosterone deficiency in adult males has been associated with declining bone mass, muscle strength, reduced energy levels and altered sexual function (Araujo et al, 2007). In male cancer survivors, Howell et al (2000) reported reduced bone mineral density in patients with mild Leydig cell impairment, and testosterone levels has been reported to be negatively correlated to insulin, total body fat mass/total trunk fat mass and BMI (Huddart and Norman, 2003; Greenfield et al, 2007). With this background, it is of clinical importance to identify male cancer survivors with endocrine hypogonadism. In this context, it is surprising that only three of the included patients reported testosterone substitution therapy at the time of the survey, whereas endocrine hypogonadism was found in one-third of our patients.

Testosterone replacement therapy is a challenging issue in both male cancer survivors and in the general male population. Age has a significant influence on physiological testosterone levels. To evaluate endocrine hypogonadism at least two morning blood samples are needed and clinical symptoms, age and possible contraindications for testosterone substitution have to be considered. Owing to these caveats our study patients' with endocrine hypogonadism identified in this study were offered repeated hormone analyses and clinical examination at the outpatient clinic before any testosterone substitution was initiated.

There are some limitations to be discussed:

The compliers were older at survey than the non-compliers. This may have caused a biased patient sample with a slightly higher proportion of hypogonadism in our patient sample than in the total population of male lymphoma survivors.

Our patients' age ranged from 21 to 73 years at survey and we found a fivefold increase in the risk of endocrine hypogonadism in men aged above 50 years at survey compared to those less than 40 years at survey. Similarly, Howell et al (1999) reported increasing risk of chemotherapy-induced Leydig cell damage with increasing age, and an age-dependent decline in testosterone levels was reported by Greenfield et al (2007). Studies from the general population have shown age-related decrease in testosterone values (Svartberg et al, 2003; Mohr et al, 2005). As our normal range for testosterone was not age adjusted, this may have lead to a comparatively broad allocation of older men to the group of endocrine hypogonadism. As a further limitation we could not consider chronic co-morbidity or any long-lasting medication in our patients, which might also have influenced our findings.

Seven patients registered in the database with both HL and NHL had their gonadal hormones assessed, and were grouped according to their first diagnosis. This may have biased the results because their treatment consisted of combinations of different types of chemotherapy.

The strength of this cross-sectional study is that it consists of a large series of male survivors after both HL and NHL with known treatment details and gonadal hormones assessed by a single laboratory. We achieved a compliance of $45 \%$, which we consider satisfactory taken into account that this long-term follow-up survey implied blood sampling at a GP's office.

The results of this study implicate that gonadal hormones should be assessed regularly in male lymphoma survivors, especially after treatment with high-dose alkylating agents and HDT and in male patients 50 years and older. If gonadal hormones indicate hypogonadism, further analyses and clinical evaluation should evaluate the need of testosterone substitution to avoid the development of serious health problems.

\section{ACKNOWLEDGEMENTS}

We are very thankful for the practical help from Siri L Hess and Vigdis Opperud at the National Resource Centre for long-term studies after Cancer. This project has been financed with the aid of EXTRA funds from the Norwegian Foundation for Health and Rehabilitation and The Norwegian Cancer Society. 


\section{REFERENCES}

Abrahamsen AF, Hannisdal E, Nome O, Holte H, Hager B, Langholm R, Kvaloy S (1996) Clinical stage I and II Hodgkin's disease: long-term results of therapy without laparotomy. Experience at one institution. Ann Oncol 7: $145-150$

Araujo AB, Esche GR, Kupelian V, O’Donnell AB, Travison TG, Williams RE, Clark RV, McKinlay JB (2007) Prevalence of symptomatic androgen deficiency in men. J Clin Endocrinol Metab 92: 4241 - 4247

Aurlien E, Holte H, Kvaloy S, Jakobsen E, Rusten LS, Kvalheim G (2001) Combination chemotherapy containing mitoguazone, ifosfamide, methotrexate, etoposide (MIME) and G-CSF efficiently mobilize peripheral blood progenitor cells in heavily pre-treated relapsed lymphoma patients. Eur J Haematol Suppl 64: 14-20

Blystad AK, Holte H, Kvaloy S, Smeland E, Delabie J, Kvalheim G (2001a) High-dose therapy in patients with Hodgkin's disease: the use of selected $\mathrm{CD} 34(+)$ cells is as safe as unmanipulated peripheral blood progenitor cells. Bone Marrow Transplant 28: 849-857

Blystad AK, Torlakovic E, Holte H, Kvaloy S, Lenschow E, Kvalheim G (2001b) CD34(+) cell enrichment depletes atypical CD30(+) cells from PBPC grafts in patients with HD. Cytotherapy 3: 295-305

Botchan A, Hauser R, Gamzu R, Yogev L, Lessing JB, Paz G, Yavetz H (1997) Sperm quality in Hodgkin's disease versus non-Hodgkin's lymphoma. Hum Reprod 12: $73-76$

Evensen SA, Brinch L, Tjonnfjord G, Stavem P, Wisloff F (1994) Estimated 8 -year survival of more than $40 \%$ in a population-based study of 79 adult patients with acute lymphoblastic leukaemia. $\mathrm{Br}$ J Haematol 88: 88-93

Finkelstein JS, Klibanski A, Neer RM, Greenspan SL, Rosenthal DI, Crowley Jr WF (1987) Osteoporosis in men with idiopathic hypogonadotropic hypogonadism. Ann Intern Med 106: 354-361

Fitoussi O, Eghbali H, Tchen N, Berjon JP, Soubeyran P, Hoerni B (2000) Semen analysis and cryoconservation before treatment in Hodgkin's disease. Ann Oncol 11: 679-684

Greenfield DM, Walters SJ, Coleman RE, Hancock BW, Eastell R, Davies HA, Snowden JA, Derogatis L, Shalet SM, Ross RJ (2007) Prevalence and consequences of androgen deficiency in young male cancer survivors in a controlled cross-sectional study. J Clin Endocrinol Metab 92: 3476-3482

Hagemeister FB, Tannir N, McLaughlin P, Salvador P, Riggs S, Velasquez WS, Cabanillas F (1987) MIME chemotherapy (methyl-GAG, ifosfamide, methotrexate, etoposide) as treatment for recurrent Hodgkin's disease. J Clin Oncol 5: 556-561

Hollender A, Kvaloy S, Lote K, Nome O, Holte H (2000) Prognostic factors in 140 adult patients with non-Hodgkin's lymphoma with systemic central nervous system (CNS) involvement. A single centre analysis. Eur J Cancer 36: $1762-1768$

Holte H, Mella O, Wist E, Telhaug R, Hannisdal E, Abrahamsen AF (1996) ChlVPP is as effective as alternating ChlVPP/ABOD in advanced stage Hodgkin's disease. Acta Oncol 35(Suppl 8): 73-80

Howell SJ, Radford JA, Adams JE, Shalet SM (2000) The impact of mild Leydig cell dysfunction following cytotoxic chemotherapy on bone mineral density (BMD) and body composition. Clin Endocrinol (Oxf) 52: 609-616

Howell SJ, Radford JA, Ryder WD, Shalet SM (1999) Testicular function after cytotoxic chemotherapy: evidence of Leydig cell insufficiency. J Clin Oncol 17: 1493 - 1498

Howell SJ, Shalet SM (2001) Testicular function following chemotherapy. Hum Reprod Update 7: 363-369

Huddart RA, Norman A (2003) Changes in BMI after treatment of testicular cancer are due to age and hormonal function and not chemotherapy. $\mathrm{Br} \mathrm{J}$ Cancer 89: 1143 - 1144

Kiserud CE, Fossa A, Holte H, Fossa SD (2007) Post-treatment parenthood in Hodgkin's lymphoma survivors. Br J Cancer 96: 1442 - 1449
Lee SJ, Schover LR, Partridge AH, Patrizio P, Wallace WH, Hagerty K, Beck LN, Brennan LV, Oktay K (2006) American Society of Clinical Oncology recommendations on fertility preservation in cancer patients. J Clin Oncol 24: $2917-2931$

Merk K, Idestrom K, Johansson B, Kimby E, Lindemalm C, Osby E, Bjorkholm M (1991) Mitoxantrone, etoposide, cytarabine and prednisone as salvage therapy for refractory non-Hodgkin lymphoma (NHL) and alternated with CHOP in previously untreated patients with NHL. Eur J Haematol 46: $33-37$

Mohr BA, Guay AT, O’Donnell AB, McKinlay JB (2005) Normal, bound and nonbound testosterone levels in normally ageing men: results from the Massachusetts Male Ageing Study. Clin Endocrinol (Oxf) 62: 64-73

Nord C, Bjoro T, Ellingsen D, Mykletun A, Dahl O, Klepp O, Bremnes RM, Wist E, Fossa SD (2003) Gonadal hormones in long-term survivors 10 years after treatment for unilateral testicular cancer. Eur Urol 44: $322-328$

Rueffer U, Breuer K, Josting A, Lathan B, Sieber M, Manzke O, Grotenhermen FJ, Tesch H, Bredenfeld H, Koch P, Nisters-Backes H, Wolf J, Engert A, Diehl V (2001) Male gonadal dysfunction in patients with Hodgkin's disease prior to treatment. Ann Oncol 12: 1307-1311

Seidemann K, Tiemann M, Schrappe M, Yakisan E, Simonitsch I, JankaSchaub G, Dorffel W, Zimmermann M, Mann G, Gadner H, Parwaresch R, Riehm H, Reiter A (2001) Short-pulse B-non-Hodgkin lymphoma-type chemotherapy is efficacious treatment for pediatric anaplastic large cell lymphoma: a report of the Berlin-Frankfurt-Munster Group Trial NHL-BFM 90. Blood 97: 3699-3706

Smeland S, Blystad AK, Kvaloy SO, Ikonomou IM, Delabie J, Kvalheim G, Hammerstrom J, Lauritzsen GF, Holte H (2004) Treatment of Burkitt's/ Burkitt-like lymphoma in adolescents and adults: a 20-year experience from the Norwegian Radium Hospital with the use of three successive regimens. Ann Oncol 15: $1072-1078$

Svartberg J, Midtby M, Bonaa KH, Sundsfjord J, Joakimsen RM, Jorde R (2003) The associations of age, lifestyle factors and chronic disease with testosterone in men: the Tromso Study. Eur J Endocrinol 149: $145-152$

Sweetenham JW, Santini G, Qian W, Guelfi M, Schmitz N, Simnett S, Nagler A, Holte H, Kvaloy S, Bruzzi P, Goldstone AH (2001) High-dose therapy and autologous stem-cell transplantation $v s$ conventional-dose consolidation/maintenance therapy as postremission therapy for adult patients with lymphoblastic lymphoma: results of a randomized trial of the European Group for Blood and Marrow Transplantation and the United Kingdom Lymphoma Group. J Clin Oncol 19: 2927-2936

van der Kaaij MA, Heutte N, Le SN, Raemaekers JM, Simons AH, Carde P, Noordijk EM, Ferme C, Thomas J, Eghbali H, Kluin-Nelemans HC, Henry-Amar M (2007) Gonadal function in males after chemotherapy for early-stage Hodgkin's lymphoma treated in four subsequent trials by the European Organisation for Research and Treatment of Cancer: EORTC Lymphoma Group and the Groupe d'Etude des Lymphomes de l'Adulte. J Clin Oncol 25: 2825-2832

Viviani S, Ragni G, Santoro A, Perotti L, Caccamo E, Negretti E, Valagussa P, Bonadonna G (1991) Testicular dysfunction in Hodgkin's disease before and after treatment. Eur J Cancer 27: 1389- 1392

Viviani S, Santoro A, Ragni G, Bonfante V, Bestetti O, Bonadonna G (1985) Gonadal toxicity after combination chemotherapy for Hodgkin's disease. Comparative results of MOPP vs ABVD. Eur J Cancer Clin Oncol 21: $601-605$

Whitehead E, Shalet SM, Blackledge G, Todd I, Crowther D, Beardwell CG (1982) The effects of Hodgkin's disease and combination chemotherapy on gonadal function in the adult male. Cancer 49: 418-422 